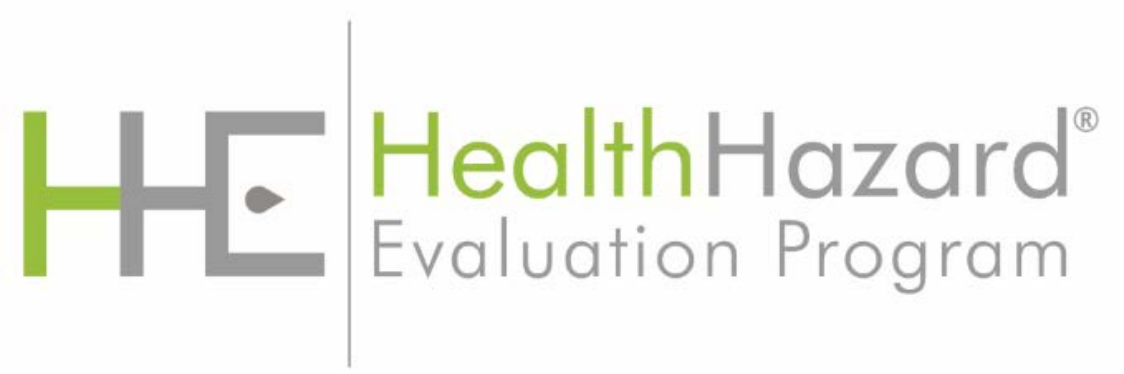

\title{
Evaluation of Health Symptoms After a Law Enforcement Operation
}

HHE Report No. 2019-0114-3358

October 2019 


\section{Jennifer Hornsby-Myers, MS, CIH}

\section{Douglas Trout, MD, MHS}

Desktop Publisher: Jennifer Tyrawski

Editor: Cheryl Hamilton

Medical Field Assistance: Christopher Iverson

Data Support: Christopher Iverson

Keywords: North American Industry Classification System (NAICS) 922120 (Police Protection), New York, Law Enforcement, Police, Respiratory Symptoms, Influenza-like Illness, Search Warrant Execution, Law Enforcement Operation, Illicit Drugs, Explosives, Guns

\section{Disclaimer}

The Health Hazard Evaluation Program investigates possible health hazards in the workplace under the authority of the Occupational Safety and Health Act of 1970 [29 USC 669a(6)]. The Health Hazard Evaluation Program also provides, upon request, technical assistance to federal, state, and local agencies to investigate occupational health hazards and to prevent occupational disease or injury. Regulations guiding the Program can be found in Title 42, Code of Federal Regulations, Part 85; Requests for Health Hazard Evaluations [42 CFR Part 85].

\section{Availability of Report}

Copies of this report have been sent to the employer and employees at the law enforcement agency. The state and local health departments and the Occupational Safety and Health Administration Regional Office have also received a copy. This report is not copyrighted and may be freely reproduced.

\section{Recommended Citation}

NIOSH [2019]. Evaluation of health symptoms after a law enforcement operation. By Chiu S, Hornsby-Myers J, Trout D. Cincinnati, OH: U.S. Department of Health and Human Services, Centers for Disease Control and Prevention, National Institute for Occupational Safety and Health, Health Hazard Evaluation Report 2019-0114-3358, 


\section{Main Report}

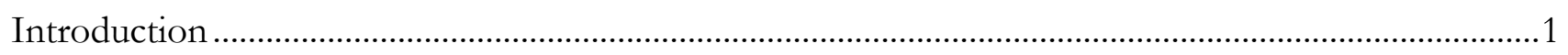

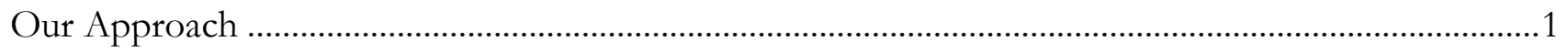

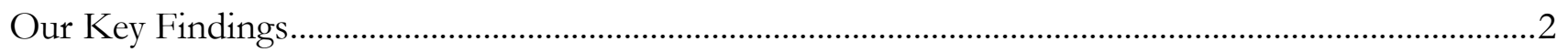

Our Recommendations .............................................................................................................

\section{Supporting Technical Information}

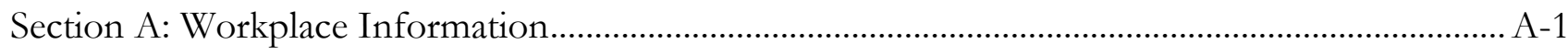

Section B: Methods, Results, and Discussion …………………………………………………... B-1

Methods: Description of the December 2018 Operation ................................................................ B-1

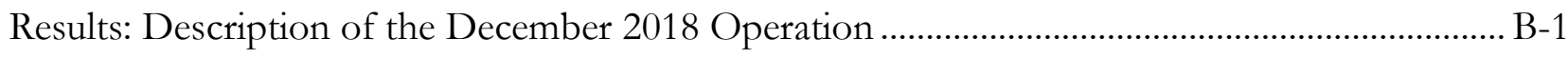

Methods: Employee Health Assessment ………………………………………………….... B-3

Results: Employee Health Assessment …………………………………………………..... B-4

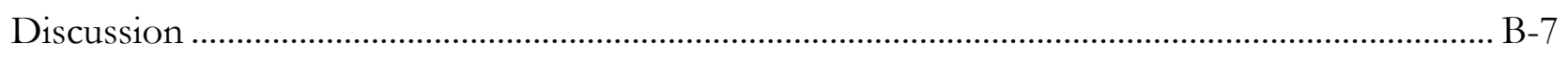

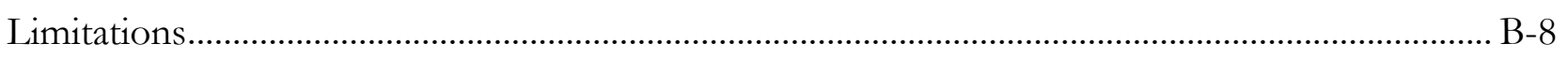

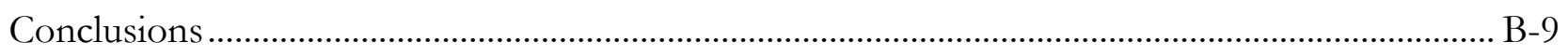

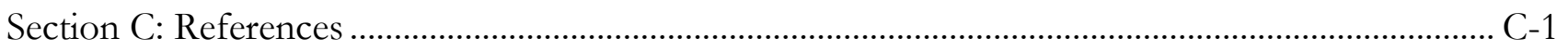


This page left intentionally blank 


\section{Introduction}

\section{Request}

A law enforcement agency requested a health hazard evaluation concerning illnesses among multiple law enforcement officers (LEOs) from multiple agencies who participated in a law enforcement operation (operation). Illnesses among LEOs were reported to have begun the day of or soon after the operation. The operation consisted of taking a subject into custody and executing a search warrant at a residence. The law enforcement agency was concerned that the reported illnesses may have been associated with work-related exposures during the operation.

\section{Background}

LEOs from multiple law enforcement agencies took part in the operation, which was coordinated by the agency who made the evaluation request. Activities included taking the suspect into custody, making entry into the residence and ensuring there were no threats inside the residence, searching for evidence, and processing the collected evidence. Twelve days after the operation, environmental wipe samples were taken at the residence.

To learn more about the workplace, go to Section A in the Supporting Technical Information

\section{Our Approach}

In March 2019, we visited the law enforcement agency that coordinated the operation. During the visit, we completed the following activities:

- Interviewed employees about their work and health.

- Spoke with officials of the coordinating law enforcement agency and officials of the county where the operation occurred.

We also reviewed these relevant records:

- De-identified spreadsheet with information about work and health for LEOs who participated in the operation.

- Forensic laboratory results for evidence collected during the operation.

- Environmental testing results of samples taken at the residence after the operation.

- Documents related to the operation.

To learn more about our methods, go to Section B in the Supporting Technical Information 


\section{Our Key Findings}

\section{LEOs found illicit drugs, guns, and explosive devices in the residence during the operation}

- Thirty-eight LEOs from multiple agencies participated in the operation. Two did not enter the residence.

- Job tasks varied during the operation. The special weapons and tactics (SWAT) team made initial entry and secured the residence. Bomb technicians cleared the residence for explosives. The evidence response team (ERT) photographed and sketched the residence. ERT and counterterrorism (CT-1) squad members searched the residence thoroughly and processed evidence collected.

- LEOs reported this residence was similar to residences seen in other operations.

- Some LEOs wore personal protective equipment (PPE) such as gloves, respirators, long-sleeved clothing, and eye protection during the operation. LEOs reported having facial hair while wearing a respirator or putting on and taking off a respirator while wearing potentially contaminated gloves.

- Forensic laboratory testing showed the presence of cocaine, marijuana, and low explosive black powder in the residence.

- Environmental samples collected by hazardous materials (HAZMAT) teams 12 days after the operation did not detect the presence of bioterrorism agents and toxins tested.

\section{Symptoms experienced by many LEOs were consistent with an influenza-like illness} and likely not related to illicit drugs or other substances in the residence

- Twenty-five of the $38(66 \%)$ LEOs who participated in the operation reported at least one symptom. One LEO reported symptoms on the morning before the operation, and 24 LEOs reported symptoms after the operation. None reported symptoms that began during the operation.

- The timing and types of symptoms reported were not consistent with symptoms reported after exposure to illicit drugs or other substances identified in the residence.

- The most common symptoms were fatigue, body aches, runny or stuffy nose, and headache. Four LEOs reported mostly gastrointestinal symptoms.

- Eleven LEOs reported influenza-like illness, defined as fevers or chills and cough or sore throat. This included $29 \%$ of all LEOs who participated in the operation and $44 \%$ of symptomatic LEOs.

o CT-1 squad members were approximately four times more likely to have influenza-like illness than non-CT-1 squad members. 
o LEOs who received influenza vaccines during the 2018-2019 season were less likely to have influenza-like illness than LEOs who were not vaccinated.

To learn more about our results, go to Section B in the Supporting Technical Information

\section{Our Recommendations}

Benefits of Improving Workplace Health and Safety:
个 Improved employee health and well-being
$\uparrow$ Enhanced image and reputation
$\uparrow$ Better workplace morale
$\uparrow$ Superior products, processes, and services
$\uparrow$ Easier employee recruiting and retention
$\uparrow$ May increase overall cost savings

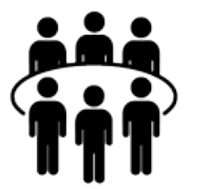

The recommendations below are based on the findings of our evaluation. We encourage the law enforcement agency to use a health and safety committee to discuss our recommendations and develop an action plan. Both employee representatives and management representatives should be included on the committee. Helpful guidance can be found in "Recommended Practices for Safety and Health Programs" at https://www.osha.gov/shpguidelines/index.html.

\section{Recommendation 1: Include health and safety considerations when planning law enforcement activities}

Why? As part of the evaluation, we asked LEOs about work practices during the operation. We identified areas for improvement, especially related to minimizing the potential for work-related exposure to illicit drugs (including fentanyl and many other drugs being used illicitly). Cocaine was found inside the residence.

Fentanyl and other drugs pose a potential hazard to responders (such as LEOs, firefighters, and emergency medical services personnel) who come into contact with them in the course of their work. Possible exposure routes to fentanyl and other drugs can vary based on the source and form of the drug. Responders are most likely to encounter fentanyl and its analogues in powder (including compressed powder), tablet, and/or liquid form. Potential exposure routes of greatest concern include inhalation, mucous membrane contact, ingestion, and percutaneous exposure (e.g., needlestick). Any of these exposure routes can potentially result in toxic effects. Brief skin contact with powdered fentanyl or its analogues is not expected to lead to toxic effects if any visible contamination is promptly removed.

The standard safe operating procedures and PPE recommendations in the current guidance on preventing occupational exposure to fentanyl among emergency responders mentioned below will also protect against exposure to other illicit drugs in powder form. 
Follow guidance from the National Institute for Occupational Safety and Health Topic Page entitled "Fentanyl: Preventing Occupational Exposure to Emergency Responders"

(https://www.cdc.gov/niosh/topics/fentanyl/risk.html).

Specific recommendations relevant to this evaluation include the following actions:

- Avoid performing tasks or operations that may make fentanyl or other drugs airborne.

- Do not touch the eyes, mouth, and nose after touching any surface potentially contaminated with fentanyl or other drugs.

- Wash exposed skin with soap and water (or just water) immediately after a potential exposure and after leaving a scene where fentanyl or other drugs are known or suspected to be present. Do not use hand sanitizers or bleach solutions to clean skin potentially contaminated with fentanyl or other drugs.

- Wear nitrile gloves when fentanyl or other drugs are suspected to be present. Train LEOs (1) on how to remove gloves safely and (2) to change or remove gloves after completing work tasks that involve potential contamination with fentanyl or other drugs and before working in an area where fentanyl or other drugs are not suspected to be present. When fentanyl or other drugs are not visible, but suspected to be present, exposure level can be considered "minimal" according to National Institute for Occupational Safety and Health (NIOSH) guidance for emergency responders.

- Based on the situation at the scene, PPE that is more protective might be considered, as outlined in the current guidance.

\section{Conduct a job safety analysis with occupational safety and health experts or others with expertise on PPE and law enforcement work.}

The safety analysis should address these specific topics:

- Criteria for determining what level of PPE is needed for each law enforcement operation and adjusting levels of PPE as conditions change during operations.

- Training LEOs on the timing for putting on PPE in conditions that are unsecured or unsafe from a law enforcement perspective.

- Criteria for determining which employees should be enrolled in a respiratory protection program.

- Ensuring LEOs in the respiratory protection program know how to properly use a respirator along with all the equipment they might carry, such as helmets, body cameras, and radios. 
- Training LEOs on changing gloves and disposing of used gloves after performing tasks with potential for contamination. Tasks include handling evidence and searching or handcuffing subjects who might have recently handled them.

\section{Ensure all components of a respiratory protection program are implemented.}

- Ensure that employees in the respiratory protection program are medically evaluated, fit tested, and trained.

- Ensure that employees do not have facial hair that can interfere with the sealing surface of tight-fitting respirators.

- Guidelines for putting on and taking off a disposable respirator are available in a NIOSH video entitled Properly Using PPE to Avoid Illicit Drug Exposure for First Responders available at https://www.cdc.gov/niosh/topics/fentanyl/toolkit.html.

\section{Keep LEOs up-to-date on all new policies and procedures.}

\section{Recommendation 2: Improve ways to prevent the spread of infection}

Why? Having many sick employees at the same time can decrease staffing levels and the agency's ability to carry out its mission.

Many LEOs who participated in the operation developed symptoms. Approximately $40 \%$ of the symptomatic LEOs had an influenza-like illness.

How? At your workplace, we recommend these specific actions:

\section{Encourage all employees to get an annual seasonal flu vaccine.}

- The Centers for Disease Control and Prevention (CDC) recommend that everyone 6 months of age or older get a flu vaccine each year. More information about the flu vaccine can be found at https://www.cdc.gov/flu/prevent/keyfacts.htm.

- Consider if it is feasible to host a flu vaccine clinic at the workplace.

- Inform employees on where they can get a flu vaccine in their community. 


\section{Tell employees to stay home when they are sick.}

- Encourage employees to self-assess for symptoms and stay home if they are sick.

- Advise employees to stay home until at least 24 hours after their fever is gone without the use of fever-reducing medicines. Fever means a temperature of $100^{\circ}$ Fahrenheit (37.8 $8^{\circ}$ Celsius) or higher.

- Ask sick employees to go home. Employees who appear to have flu symptoms when they arrive at work or become sick during the workday should be promptly separated from others and asked to go home.

- Ensure that sick leave policies and staffing levels or scheduling arrangements will encourage sick employees to stay home.

\section{Promote hand hygiene practices.}

- Remind employees that washing hands with soap and water is the best way to reduce the number of microbes on hands in most situations.

- Keep alcohol-based hand sanitizer near commonly touched surfaces at headquarters (for example, near keypads) for use when hands are not visibly dirty or greasy. Hand sanitizer is not recommended at scenes with potential for illicit drug exposure.

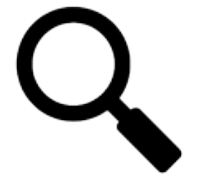

\section{Obtain more information about how to prevent the spread of influenza at} work at https://www.cdc.gov/flu/business/index.htm.

\section{Recommendation 3: Consider an indoor environmental quality assessment of the Sensitive Compartmented Information Facility}

Why? During the course of our evaluation, some employees reported that they thought there was not enough air circulation in the Sensitive Compartmented Information Facility (SCIF). Although this was not the focus of our evaluation, poor indoor environmental quality could affect employee satisfaction and productivity and should be addressed. 
Supporting Technic al Information

Evaluation of Health Symptoms After a Law

Enforcement Operation

HHE Report No. 2019-0114-3358

October 2019 


\section{Section A: Workplace Information}

The law enforcement agency (Agency) that made the health hazard evaluation (HHE) request is a federal agency within the Department of Justice. It divides its investigations into a number of programs, including counterterrorism, organized crime and drugs, and weapons of mass destruction. The Agency works with other federal, state, and local law enforcement agencies. In addition to its national headquarters, the Agency has field offices throughout the country.

This operation involved a field office with a headquarters building and a satellite building within the same city, as well as three satellite offices in the surrounding area. This field office houses 219 LEOs, which include 192 LEOs employed by the Agency and 27 LEOs employed by other agencies assigned to work at the Agency. We refer to them collectively as affiliated LEOs. The field office headquarters building contains a SCIF. 


\section{Section B: Methods, Results, and Discussion}

Our evaluation objectives were the following:

- Characterize the pattern of symptoms and illnesses reported among LEOs who participated in the operation.

- Make recommendations for occupational safety and health actions to be considered during similar work activities in the future.

\section{Methods: Description of the December 2018 Operation}

We visited the Agency on March 18 and 19, 2019. During the visit, we met with Agency representatives and conducted voluntary, confidential interviews with 27 LEOs who participated in the operation. We interviewed 21 LEOs in person and 6 LEOs via telephone. During the interviews, we discussed job activities and PPE use associated with the operation. LEOs who were in two units were classified based on their primary role when we summarized descriptive statistics.

In addition, on March 20, 2019, we met with the sheriff, the emergency services coordinator, and the public health director of the county where the operation occurred. We also reviewed the following documents:

- De-identified spreadsheet (line list) that listed the unit of 37 of the 38 LEOs who participated in the operation.

- Photographs of potential hazards inside the residence, such as guns, explosives, and substances suspected to be illicit drugs.

- Forensic laboratory results for evidence collected during the operation.

- Biological agent and toxin testing results for surface samples taken at the residence 12 days after the operation.

- Executive summary of the operation prepared by the sheriff's office.

- Partially redacted emails about the operation.

- Notes from the county public health department about the operation.

Results: Description of the December 2018 Operation

\section{Events}

On December 14, 2018, the Agency coordinated a law enforcement operation that involved taking a suspect into custody and executing a search warrant on a private residence. Thirty-eight LEOs participated in this operation. Of these, 35 LEOs were affiliated with the Agency: 26 were Agency employees and 9 were employees of other law enforcement agencies who were assigned to work at the Agency. The remaining three employees were nonaffiliated LEOs from local law enforcement agencies in the area.

B-1 
The residence consisted of two stories. The first floor had a living room and a kitchen. The second floor had three bedrooms, a bathroom, and a hallway with attic access. Two individuals reportedly lived at the residence: the suspect and an adult family member. A child reportedly visited the residence frequently but did not live there. These three individuals were reportedly not exhibiting any health symptoms at the time of the operation.

Prior to the operation, LEOs reported traveling to a staging area near the residence in personal or work vehicles alone or in small groups. The duration of staging for each employee varied because different units entered the residence at different times. Staging lasted up to several hours. In general, LEOs reported remaining in vehicles or outdoors for brief periods and mostly interacting with members of their own units during staging.

Job tasks before and during the operation varied by unit. A nonaffiliated deputy sheriff performed a traffic stop on the suspect's vehicle, took the suspect into custody, and transported the suspect to the sheriff's office headquarters. This deputy sheriff did not enter the residence. Two members of the CT-1 squad watched the suspect's two family members in a nearby residence. One of these CT-1 members entered the residence for up to 10 minutes at the end of the operation-the other member never entered the residence.

Among the remaining LEOs, the SWAT team $(\mathrm{n}=13)$ was responsible for initial entry into the residence and ensuring that there were no human threats throughout the residence. Next, bomb technicians $(\mathrm{n}=3)$ searched for explosive threats in the residence. A robot was used in this process. After the residence was cleared, the SWAT team and bomb technicians left the operation. The ERT $(n=6)$ photographed and sketched a diagram of the residence, performed a thorough search for evidence, and processed the evidence collected. The remaining CT-1 squad members $(n=13)$ also participated in the thorough search of the residence and evidence processing.

Interviewed LEOs reported that the residence was typical of residences seen on similar operations. They reported an odor associated with nearby industrial facilities. Loose powders were seen throughout the residence. A small safe was reportedly opened with force inside the residence and was found to contain substances suspected to be illicit drugs. During the search, substances suspected to be illicit drugs, several guns, and a few small explosive devices were recovered. Forensic laboratory testing showed the presence of cocaine, marijuana, and low explosive black powder in the residence.

Twelve days after the operation, two HAZMAT teams entered the sealed residence to collect environmental wipe samples after reports of multiple LEOs developing symptoms. Wipe samples taken on the first and second floors of the residence did not detect the presence of biological agents and toxins tested.

\section{Job Activities and PPE Use}

The 27 interviewed LEOs consisted of 10 SWAT team members, 11 CT-1 squad members, 5 ERT members, and 1 deputy sheriff. One interviewed LEO also served in the bomb technician role. Among the 27 interviewed LEOs, 25 LEOs entered the residence, spending a median of 2 hours (range: 10 minutes -6 hours) total inside the residence. Median total time in the residence varied by unit: SWAT team, 33 minutes (range: 10 minutes-2 hours); CT-1 squad, 5 hours (range: 10 minutes- 8 hours); and 
ERT, 5.5 hours (range: 5-7 hours). Among the 25 interviewed LEOs who entered the residence, $20(80 \%)$ had been on both floors of the residence.

Regarding PPE use, 24 of 25 (96\%) interviewed LEOs who entered the residence reported wearing gloves. Sixteen of these LEOs (67\%) reported wearing nitrile gloves, and three of those reported wearing a combination of nitrile and tactical gloves. Of the 25 interviewed LEOs who entered the residence, 12 (48\%) reported wearing N95 filtering facepiece respirators at some point inside. One LEO reported having facial hair while wearing a respirator during the operation, and another reported putting on and taking off the respirator with potentially contaminated gloves. Of the 25 interviewed LEOs who entered the residence, $12(48 \%)$ reported wearing eye protection and $22(88 \%)$ reported wearing longsleeved garments.

\section{Methods: Employee Health Assessment}

\section{Information Sources}

We gathered information about employee health through (1) the line list, (2) interviews, and (3) medical records.

The de-identified line list provided by the Agency included information about symptoms, medical care sought, and influenza vaccination status for 37 of the 38 LEOs who participated in the operation. This information was collected through an internal questionnaire administered by the Agency by e-mail or in person within 3.5 weeks after the operation.

Of the 27 interviewed LEOs, one was not on the line list. During the interviews, we asked questions about the following topics:

- Demographic and work information

- Symptoms experienced before, during, and after the operation

- Medical care sought

- Influenza vaccination status prior to the operation

The Agency provided an updated line list that included the names of the interviewed LEOs only so we could link information from their line list entry and their interview. We reviewed medical records for five of six interviewed LEOs who reported seeking medical care related to the operation. If information about symptoms or influenza vaccination status was available from multiple sources, we integrated it in the following order: medical records, interviews, and line list. For example, if a symptom was mentioned in the medical record but not during the interview or on the line list, we considered the symptom present in our analysis. We used only information from the line list for LEOs who were not interviewed.

\section{Data Analysis}

We summarized descriptive statistics for demographic, work, and health information. LEOs who were in two units were classified based on their primary role.

We defined a case of influenza-like illness as subjective fever or chills and either cough, sore throat, or both with symptom onset on or after December 14, 2018 in a LEO who participated in the operation. 
This case definition was based on the CDC case definition for influenza-like illness used for surveillance purposes [Budd et al. 2017]. We plotted the number of LEOs who developed symptoms by the date when a symptom in the case definition was first experienced. If this date was not available, we used the date for symptom onset in general.

To assess which characteristics were associated with meeting the case definition, we compared case and noncase LEOs using Fisher's exact test for categorical variables and the Mann-Whitney $U$ test for continuous variables. We calculated prevalence ratios (PRs) and 95\% confidence intervals (CIs) by comparing the prevalence of influenza-like illness among LEOs with and without a given characteristic. All statistical tests were two-sided, with statistical significance set at $P<0.05$. We used $\mathrm{R}$ version 3.5.1 to perform statistical analyses.

\section{Results: Employee Health Assessment}

\section{Demographic, Work, and Health Information}

Among the 27 LEOs we interviewed, the median age was 41 years (range: 32-55 years). Twenty-three $(85 \%)$ were male. Job tenure, defined as duration of employment or assignment at the current agency, was 10 years (range: $1-32$ years).

Seventeen (63\%) interviewed LEOs reported working in the field office headquarters building, of which $15(88 \%)$ reported being based in the SCIF. Some LEOs reported that they thought there was insufficient air circulation in the SCIF.

Seven interviewed LEOs reported ill contacts around the time of the operation. Of these seven, four reported ill coworkers at the Agency, two reported ill household members, and one reported ill coworkers at another job. Two affiliated LEOs who participated in the operation were identified as appearing ill during the day of the operation. Interviews and the line list revealed that among the 38 LEOs who participated in the operation, 15 (39\%) reported receiving the 2018-2019 seasonal influenza vaccine.

\section{Health Symptoms}

Among the 38 LEOs who participated in the operation, $25(66 \%)$ reported at least one symptom with onset on or after December 14, 2018. Symptom onset occurred over days, ranging from the morning of December 14 (prior to the operation) to December 22, 2018. None reported acute symptom onset during the operation. Three LEOs with symptoms described on the line list were not interviewed.

Figure B1 summarizes the symptoms reported by LEOs. The most common symptom was fatigue $(\mathrm{n}=21)$, followed by body aches $(\mathrm{n}=15)$, runny or stuffy nose $(\mathrm{n}=12)$, and headache $(\mathrm{n}=12)$. Most reported symptoms were constitutional, i.e., symptoms that can affect many different systems of the body. Four LEOs reported predominately gastrointestinal symptoms, such as stomach ache, diarrhea, and abdominal pain. Among the 27 interviewed LEOs, 6 sought medical care, and 1 was hospitalized. 


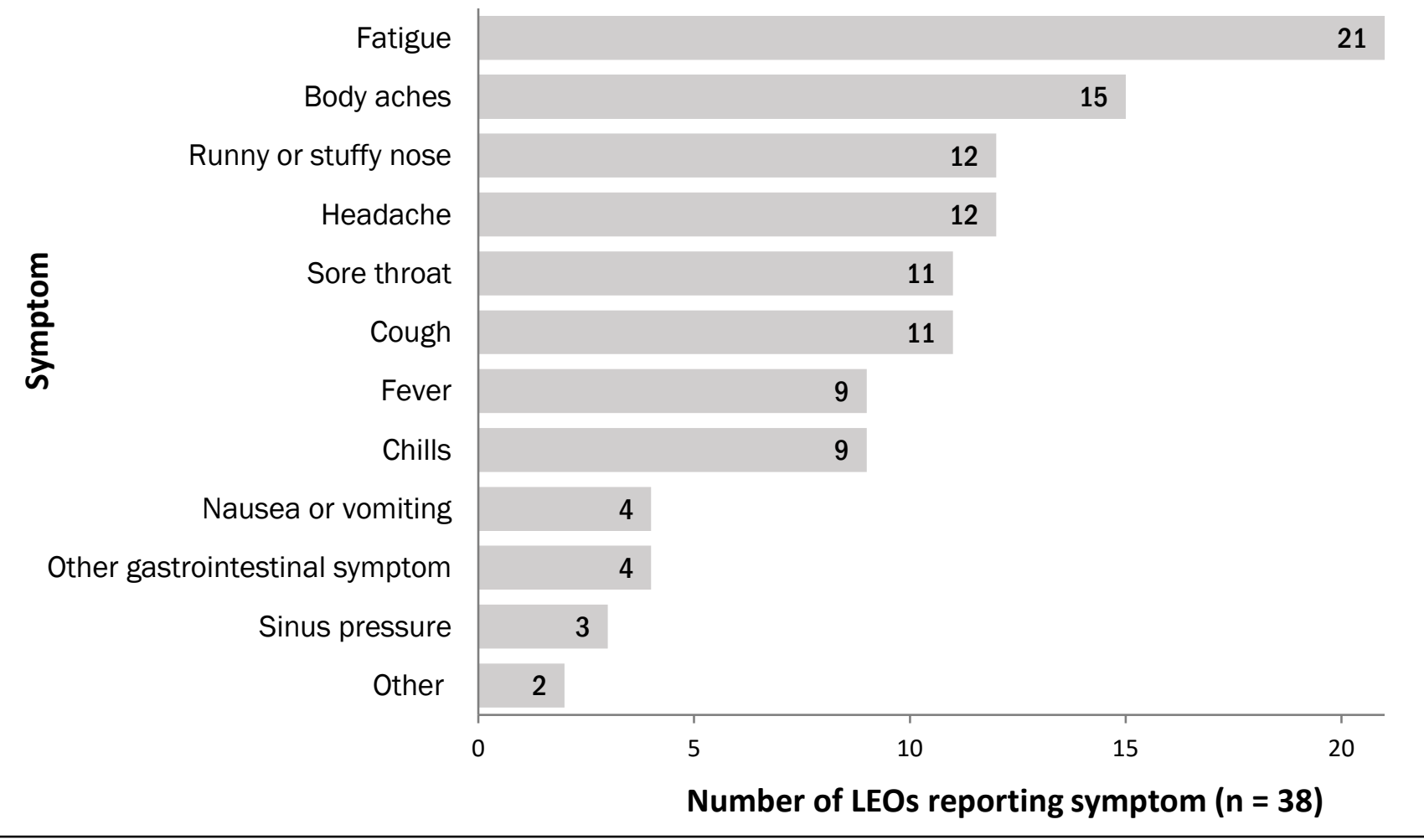

Figure B1. Bar graph showing that among the symptoms reported by LEOs who participated in the operation, fatigue, body aches, runny or stuffy nose, and headache were the most common.

\section{Influenza-like IIIness}

Eleven LEOs met the case definition for influenza-like illness (case LEOs). This corresponds to 29\% of LEOs who participated in the operation and 44\% of symptomatic LEOs. Figure B2 shows the number of case LEOs based on the date when a symptom in the case definition was first experienced. Among case LEOs, symptom onset occurred over a range of 5 days, from December 15 (the day after the operation) to December 19, 2018. Two case LEOs (18\%) reported receiving the influenza vaccination for the 2018-2019 season. 


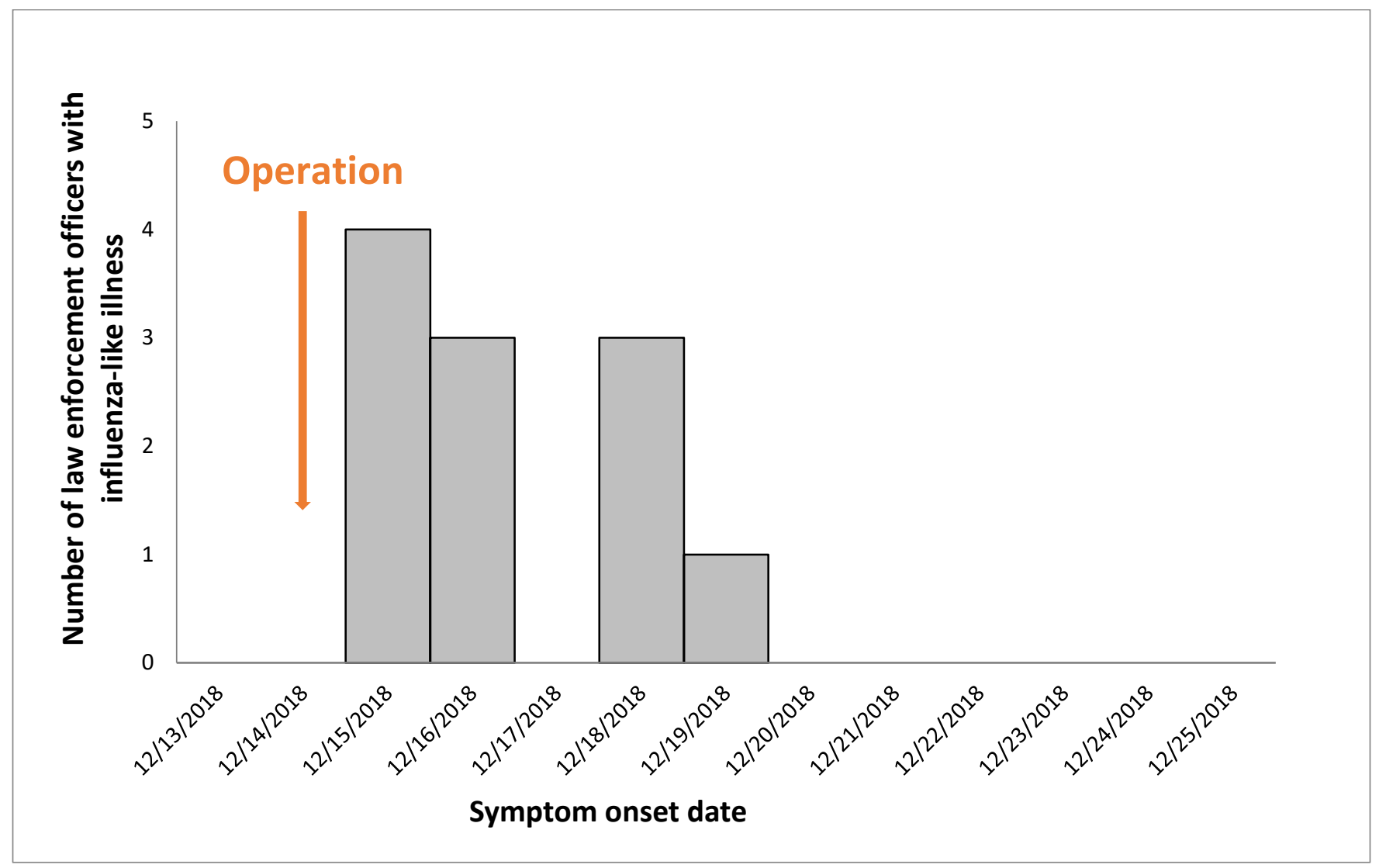

Figure B2. Epidemic curve showing that onset of influenza-like illness symptoms among 11 LEOs who met the case definition for influenza-like illness ranged from 1 to 5 days after the operation.

Ten case LEOs participated in interviews. Among the interviewed case LEOs, four received outpatient medical care and had medical records available for review. One case LEO was diagnosed with laboratory-confirmed influenza and experienced fatigue prior to the operation. Another case LEO had a negative rapid influenza diagnostic test.

CT-1 squad members were more likely to have influenza-like illness than non-CT-1 squad members (PR: 4.1; 95\% CI: 1.3, 13.0). Conversely, LEOs who received an influenza vaccine in the 2018-2019 influenza season had a lower prevalence of influenza-like illness than LEOs who did not receive an influenza vaccine (PR: 0.2; 95\% CI: 0.1,0.9).

LEOs with influenza-like illness were similar to LEOs without influenza-like illness in terms of age, sex, whether they were employees of the Agency, whether they worked in the field office headquarters building or SCIF, had been on the second floor of the residence, or used gloves or respirators during the operation. The median amount of time spent in the residence was higher among case LEOs. However, upon further examination, this apparent difference was explained by the strong association between being a member of the CT-1 squad and meeting the case definition. 


\section{Discussion}

After a multiagency operation, Agency officials became concerned because a large proportion of LEOs who participated became ill over the course of several days. The types of symptoms and the timing of symptom onset were not consistent with symptoms reported after illicit drug exposure in other recent HHEs [Chiu et al. 2019] or symptoms reported from exposures to other substances identified in the residence. While almost one third of symptomatic LEOs met the case definition for influenza-like illness, the group of symptomatic LEOs most likely had more than one type of illness. For example, four symptomatic LEOs experienced predominately gastrointestinal symptoms.

Eleven LEOs met the case definition for influenza-like illness. Other LEOs with symptoms might have had other upper respiratory tract infections such as the common cold, which, like influenza, occurs more commonly during colder months [Eccles 2002]. Another possibility is that some LEOs with influenza-like illness had some but not all of the symptoms to meet the case definition.

Influenza, an acute respiratory illness caused by infection with influenza viruses, requires laboratory testing for a definitive diagnosis. One LEO with influenza-like illness tested positive for influenza. Another LEO with influenza-like illness had a negative rapid influenza diagnostic test. Because rapid influenza diagnostic tests have varying sensitivities (ability to detect influenza when it is present), metaanalyses have concluded that while a positive result can rule in influenza, not all rapid influenza diagnostic tests can rule out influenza with a negative result [Chartrand et al. 2012; Merckx et al. 2017].

Influenza is spread from person to person via airborne droplets or contact with contaminated hands or surfaces [CDC 2018c; Riedel et al. 2019]. While people with influenza are most contagious in the first 3-4 days after their illness begins, otherwise healthy adults may be able to infect others starting 1 day before symptoms develop and up to 5-7 days after becoming sick [CDC 2015, 2018a]. This timeline is consistent with transmission of influenza-like illness over the 5-day period when case LEOs began to develop symptoms.

We found that CT-1 squad members were approximately four times more likely to have influenza-like illness than non-CT-1 squad members. We learned that LEOs tended to mostly interact with other members of their own units during the operation. Members of the same unit are more likely to interact with each other more closely than with members of other units during this operation and at other times. More frequent or closer contact between members of one unit increases the likelihood of influenza-like illness transmission within a unit than between members of different units.

The timing of illness and the higher proportion of illness among members of one unit do not allow definitive conclusions about whether one person or unit was the source of illness for others and whether transmission occurred during the operation. However, taking steps to prevent the spread of seasonal influenza at the workplace is prudent. Influenza imposes a significant disease burden. For example, in the 2018-2019 season, an estimated 37.4-42.9 million people in the United States were ill with influenza [CDC 2019a]. U.S. employees miss approximately 17 million workdays due to influenza each year [Molinari et al. 2007; NIOSH 2018]. Studies based on modeling have shown that workplaces account for approximately 16\% of influenza transmission [Edwards et al. 2016]. 
A yearly influenza vaccine is the single best way to prevent seasonal influenza. In this evaluation, 39\% of LEOs who participated in the operation reported influenza vaccination during the 2018-2019 season. As of mid-November 2018, flu vaccination coverage among adults aged $\geq 18$ years for the 2018-2019 season was estimated to be 44.9\% [CDC 2018b]. LEOs who received an influenza vaccine in the 2018-2019 influenza season had a lower prevalence of influenza-like illness than LEOs who did not receive an influenza vaccine. Most but not all of these vaccinations reportedly occurred before the operation. Employers can take actions to encourage flu vaccinations among employees [CDC 2019c]. Other workplace strategies for preventing influenza include encouraging employees to not work when ill and promoting preventive actions such as hand hygiene [CDC 2019b].

While the symptoms experienced by LEOs in this operation did not appear to be associated with exposure to illicit drugs, we identified some areas for improvement with job tasks and work practices. $\mathrm{NIOSH}$ has issued interim guidance on how to protect emergency responders such as LEOs from exposure to fentanyl and its analogues [NIOSH 2017]. We believe that this current NIOSH guidance is applicable to this operation, even though drugs other than fentanyl were involved in this operation.

Illicit fentanyl and its analogues are increasingly being mixed with other drugs, particularly cocaine [CDC 2018a]. In this operation, a safe located inside the residence was reportedly opened with force. That action could potentially cause substances around or inside the safe to become airborne, possibly leading to inhalation or mucous membrane exposure, which are the routes of exposure of the greatest concern. In addition, PPE use inside the residence varied, ranging from $96 \%$ for gloves to $48 \%$ for N95 filtering facepiece respirators. One LEO reported having facial hair during respirator use, which can interfere with the respirator's seal and thus its ability to protect against contaminants. Another LEO reported putting on and taking off the respirator while wearing potentially contaminated gloves. These practices highlight the need for training about how to correctly wear a respirator and the correct sequence for putting on and removing gloves and respirators to avoid potential exposure.

\section{Limitations}

One limitation of our evaluation is that not all LEOs who participated in the operation were interviewed. As a result, the type and level of detail in the information used for this analysis varied. For example, we obtained information such as age, sex, and whether there were ill contacts around the time of the operation during interviews. The line list might not have captured enough detail about symptoms to accurately classify LEOs who were not interviewed as cases or noncases, leading to misclassification bias. However, most LEOs who were not interviewed did not report any symptoms on the line list, and information from the line list was sufficient to classify one LEO as meeting the case definition. Another limitation is that most symptoms were based on self-report, because most LEOs did not seek medical care. Interviews occurred approximately 3 months after the operation, which might have resulted in decreased recall. Thus, we used medical records and the line list for additional information whenever possible. Medical records contained detailed information collected by medical professionals shortly after symptom onset. Information from the line list was collected shortly after the operation. 


\section{Conclusions}

After a multiagency operation, 25 of 38 (66\%) LEOs who participated experienced health symptoms over the course of several days, although none became acutely ill during the operation. The symptoms and timing of symptom onset suggest a cluster of LEOs with influenza-like illness. Improving infection prevention practices and annual influenza vaccination might prevent similar occurrences in the future. 


\section{Section C: References}

\section{Illicit Drugs}

CDC [2018a]. Rising numbers of deaths involving fentanyl and fentanyl analogs, including carfentanil, and increased usage and mixing with non-opioids. Health Alert Network Update 413. Atlanta, GA: U.S. Department of Health and Human Services, Centers for Disease Control and Prevention, Office of Public Health Preparedness and Response, https://emergency.cdc.gov/han/han00413.asp.

Chiu SK, Hornsby-Myers JL, de Perio MA, Snawder JE, Wiegand DM, Trout D, Howard J [2019]. Health effects from unintentional occupational exposure to opioids among law enforcement officers: two case investigations. Am J Ind Med 62(5):439-447, http://dx.doi.org/10.1002/ajim.22967.

NIOSH [2017]. Fentanyl: preventing occupational exposure to emergency responders. Cincinnati, OH: U.S. Department of Health and Human Services, Centers for Disease Control and Prevention, National Institute for Occupational Safety and Health, https://www.cdc.gov/niosh/topics/fentanyl/risk.html.

\section{Influenza-like IIIness}

Budd A, Blanton L, Grohskopf L, Campbell, A, Dugan V, Wentworth DE, Brammer L [2017]. Influenza. In: Roush, SW, Baldy LM, Hall MAK, eds. Manual for the surveillance of vaccinepreventable diseases. Atlanta, GA: Centers for Disease Control and Prevention, https://www.cdc.gov/vaccines/pubs/surv-manual/chpt06-influenza.html.

CDC [2015]. Epidemiology and prevention of vaccine-preventable diseases. Hamborsky J, Kroger A, Wolfe S, eds. 13th ed. Washington DC: Public Health Foundation, https://www.cdc.gov/vaccines/pubs/pinkbook/index.html.

CDC [2018b]. Early-season flu vaccination coverage among adults-United States, November 2018. U.S. Department of Health and Human Services, Centers for Disease Control and Prevention, National Center for Immunization and Respiratory Diseases, https://www.cdc.gov/flu/fluvaxview/nifsestimates-nov2018.htm.

CDC [2018c]. How flu spreads. Atlanta, GA: U.S. Department of Health and Human Services, Centers for Disease Control and Prevention, National Center for Immunization and Respiratory Diseases, https://www.cdc.gov/flu/about/disease/spread.htm.

CDC [2019a]. 2018-2019 U.S. flu season: preliminary burden estimates. U.S. Department of Health and Human Services, Centers for Disease Control and Prevention, National Center for Immunization and Respiratory Diseases, https://www.cdc.gov/flu/about/burden/preliminary-in-season-estimates.htm.

CDC [2019b]. Preventing the spread of flu in the workplace. Atlanta, GA: U.S. Department of Health and Human Services, Centers for Disease Control and Prevention, National Center for Immunization and Respiratory Diseases, https://www.cdc.gov/flu/business/prevent-flu-workplace.html.

CDC [2019c]. Promoting vaccination in the workplace. Atlanta, GA: U.S. Department of Health and Human Services, Centers for Disease Control and Prevention, National Center for Immunization and Respiratory Diseases, https://www.cdc.gov/flu/business/promoting-vaccines-workplace.htm. 
Chartrand C, Leeflang MM, Minion J, Brewer T, Pai M [2012]. Accuracy of rapid influenza diagnostic tests: a meta-analysis. Ann Intern Med 156(7):500-511, http://dx.doi.org/10.7326/0003-4819-156-7201204030-00403.

Eccles R [2002]. An explanation for the seasonality of acute upper respiratory tract viral infections. Acta Otolaryngol 122(2):183-191, http://dx.doi.org/10.1080/00016480252814207.

Edwards CH, Tomba GS, de Blasio BF [2016]. Influenza in workplaces: transmission, workers' adherence to sick leave advice and European sick leave recommendations. Eur J Public Health 26(3):478-485, http://dx.doi.org/10.1093/eurpub/ckw031.

Merckx J, Wali R, Schiller I, Caya C, Gore GC, Chartrand C, Dendukuri N, Papenburg J [2017]. Diagnostic accuracy of novel and traditional rapid tests for influenza infection compared with reverse transcriptase polymerase chain reaction: a systematic review and meta-analysis. Ann Intern Med 167(6):394-409, http://dx.doi.org/10.7326/M17-0848.

Molinari NA, Ortega-Sanchez IR, Messonnier ML, Thompson WW, Wortley PM, Weintraub E, Bridges CB [2007]. The annual impact of seasonal influenza in the US: measuring disease burden and costs. Vaccine 25(27):5086-5096, http://dx.doi.org/10.1016/j.vaccine.2007.03.046.

NIOSH [2018]. Influenza (flu) in the workplace. Cincinnati, OH: U.S. Department of Health and Human Services, Centers for Disease Control and Prevention, National Institute for Occupational Safety and Health, https://www.cdc.gov/niosh/topics/flu/activities.html.

Riedel S, Hobden JA, Miller S, Morse SA, Mietzner TA, Detrick B, Mitchell TG, Sakanari JA, Hotez P, Mejia R, eds. [2019]. Jawetz, Melnick, \& Adelberg's medical microbiology. 28th ed. New York, NY:

McGraw-Hill Education. 


\section{Delivering on the Nation's promise: \\ Promoting productive workplaces through safety and health research}

Get More Information

Find NIOSH products and get answers to workplace safety and health questions:

1-800-CDC-INFO (1-800-232-4636) | TTY: 1-888-232-6348

CDC/NIOSH INFO: $\underline{c d c . g o v / i n f o}$ | cdc.gov/niosh

Monthly NIOSH eNews: $\underline{c d c . g o v / n i o s h / e N e w s}$ 